\title{
Coxsackieviral infections involved in aseptic meningitis: a study in Slovakia from 2005 to 2009
}

M Sojka (martin.sojka1@gmail.com)1', L Wsólová², A Petrovičová

1. Department of Virology, Slovak Medical University, Bratislava, Slovakia

2. Department of Biostatistical Analyses, Slovak Medical University, Bratislava, Slovakia

Citation style for this article:

Sojka M, Wsólová L, Petrovičová A. Coxsackieviral infections involved in aseptic meningitis: a study in Slovakia from 2005 to 2009.

Euro Surveill. 2011;16(30):pii=19927. Available online: http://www.eurosurveillance.org/ViewArticle.aspx?Articleld=19927

Article published on 28 July 2011

A wide range of diseases is associated with enteroviruses. They are reported to be responsible for viral meningitis, especially in children, but also in adults. This study analysed infection with eight selected coxsackievirus serotypes as the cause of aseptic meningitis in 480 patients in Slovakia from 2005 to 2009 , using a quantitative assay for the detection of intrathecal antibodies. Intrathecal production of antibodies against selected coxsackieviruses was proved in $21 \%$ of these patients. A significant decrease from $35 \%$ in 2005 to $8,5 \%$ in $2009(p=0.004)$ in the proportion of patients with proven intrathecal production of virusspecific antibodies was observed during the study period. We conclude that coxsackievirus B4 was the endemic serotype in Slovakia and was responsible for most cases of coxsackieviral meningitis in the study period.

\section{Introduction}

Human enteroviruses (HEV) are ubiquitous faecalorally transmitted, small RNA viruses, belonging to the family Picornaviridae. HEV are classified into four species: human enterovirus A-D. These viruses cause a wide variety of diseases, and it is known that nonpolio enteroviruses are the most common cause of aseptic meningitis in adults as well as children [1-3]. Enteroviruses are responsible for approximately $26 \%$ of adult aseptic meningitis cases with identified causative agent [4]. Individual enteroviral serotypes are not clearly associated with particular disease syndromes, but have a propensity to cause particular symptoms [5]. Echovirus serotypes are frequently reported to be responsible for meningitis [5-7]. Among coxsackieviruses, the leading serotypes associated with central nervous system (CNS) diseases are $\mathrm{B} 1$ to $\mathrm{B} 6, \mathrm{~A} 7$ and $\mathrm{A} 9$ [6-10].

Many reports concerning enteroviral meningitis are based on diagnosis of enterovirus infection by the conventional method, i.e. virus isolation from cerebrospinal fluid (CSF), stool or throat wash (swab) in cell culture, followed by identification of virus by virus neutralisation assay using type-specific antisera $[6,7]$. This method is highly specific, but laborious and time-consuming. Another problem with this procedure is that although positive virus isolation from stool and throat confirms virus infection of the patient, it does not necessarily prove that it is the causative agent of current disease [11], considering the existing high proportion of inapparent enteroviral infections [10]. Evidence of the intrathecal production of virus-specific antibodies has been used to diagnose poliovirus [11,12], echovirus 6 , coxsackievirus B6 and A9 $[13,14]$ and other viral infections [15,16], using different approaches. A positive result demonstrates a clear link between the infection and CNS disease [11]. To our knowledge, no epidemiological study has been published to date applying this method in laboratory diagnostics of coxsackieviral meningitis in eastern and central Europe.

In 2004, the live Sabin oral polio vaccine, which had been in use since 1960 in the poliomyelitis vaccination programme, was replaced in Slovakia by the Salk inactivated polio vaccine. It is well known that two or more enteroviruses can propagate simultaneously in the alimentary tract, but multiplication of one of them may interfere with growth of the second. Thus, an active enterovirus infection may block live vaccine poliovirus replication in the gut $[17,18]$. On the other hand, vaccine poliovirus strain replicating in the gut may block the propagation of other enteroviruses. Shedding of poliovirus typically occurs one to four weeks after vaccination and may last months or years in immunocompromised individuals. The shift from live vaccine to inactivated vaccine means opening the living space in the gut for the other, competing, enteroviruses, and therefore may influence the spectrum of enteroviruses circulating in population. This study was designed to identify the role of selected coxsackievirus serotypes as the causative agents of aseptic meningitis by demonstrating intrathecal production of virus-specific neutralising antibodies. Furthermore, it aimed at defining the prevalence of these serotypes after the change in the polio vaccine in Slovakia.

\section{Materials and methods}

Pairs of CSF and serum samples from patients with viral meningitis (ICD-10 code A87) of suspected enteroviral aetiology, hospitalised in neurological and 
infectious disease departments of hospitals in all parts of Slovakia, that were sent to the National Reference Centre for the Identification of Enteric Viruses in Bratislava for analysis between January 2005 and December 2009, were included in this study.

\section{Antibody titre determination}

Titres of virus-specific neutralising antibodies in CSF and heat-inactivated sera were determined by a standard virus neutralisation test as described previously [11]. Standard coxsackievirus strains used to determine the virus-neutralising antibodies were coxsackievirus B1 (strain Conn), B2 (Ohio), B3 (Nancy), B4 (JVB), B5 (Faulkner), B6 (Schmitt), A7 (Parker), and A9 (Griggs). The standard viruses, obtained from the Institute of Sera and Vaccines (Prague, Czech Republic), were propagated in Vero cells and the virus serotypes were periodically verified using standard LBM Pools (Lim Benyesh-Melnick antiserum pools from Statens Serum Institut, Copenhagen, Denmark). The lowest serum and CSF dilutions that were analysed for the presence of virus-neutralising antibodies were 1:8 for serum and 1:2 for CSF. Titres of virus-neutralising antibodies were expressed as the reciprocals of the highest dilution of serum or CSF that showed neutralisation of virus. Titres of virus-specific antibodies were used to calculate the serum/CSF antibody titre ratio for each individual. Based on our previous experience with laboratory findings and the clinical course of the disease, the CSF and serum sample pair was considered to be positive for the intrathecal antibody production if a ratio of the serum and CSF titres was less than 100. This shows a relative increase in the level of virus-specific antibodies in the CSF compared with the serum and indicates local (intrathecal) antibody production linked to acute infection with a given virus type. Currently, there is no agreed standard cut-off value for serum/CSF titre ratio indicating intrathecal production of specific antibodies; various authors have used different values (32-400) depending on the viruses and methods used $[11,14,19,20]$. The presence of virus-neutralising antibodies against a given serotype in the serum (without proven intrathecal antibody production) was

\section{FIGURE 1}

Age structure of patients with aseptic meningitis, Slovakia, 2005-2009 $(\mathrm{n}=480)$

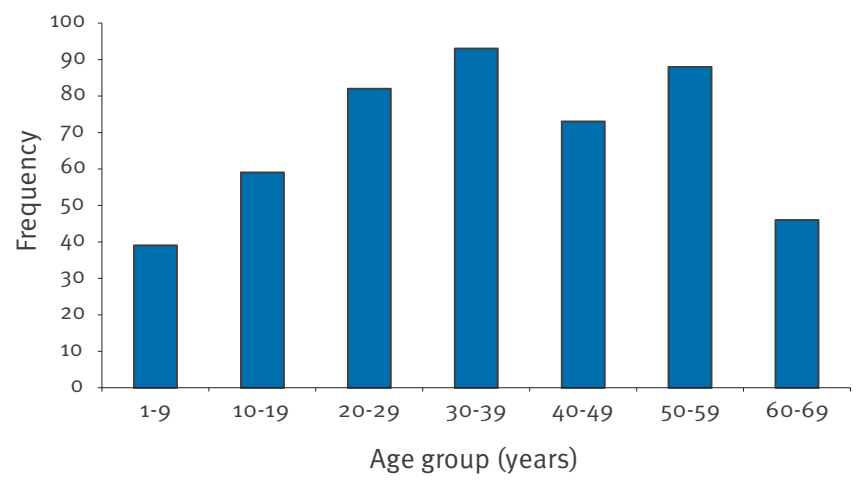

considered only as a sign of previous infection with this virus type.

\section{Statistical analysis}

The trend in the proportion of patients with proven intrathecal antibody production during the five years of the study was determined by means of linear regression. Statistical software SPSS 16.0 was used.

\section{Results}

Samples from 480 patients ( 214 men and 266 women) were analysed during the study, ranging between 43 and 147 patients per year. The median age was 36 years, ranging from 1 to 69 years (Figure 1).

During the study period, intrathecal production of virus-specific neutralising antibodies against the eight selected coxsackieviruses was shown in $100(21 \%)$ patients, ranging between nine and 30 per year. A statistically significant decrease $(p=0.004)$ in the proportion of positive cases was observed over time, from $35 \%$ in 2005 to $8.5 \%$ in 2009 (Figure 2). The highest titre of antibodies against coxsackieviruses measured in a serum sample was 2,048 .

In the 100 patients with proven intrathecal antibody production against the studies viruses, the aetiological agents were identified as follows: 46 coxsackievirus serotype $B_{4}, 19$ serotype $B_{3}, 16$ serotype $B_{5}$, eight serotype $A 9$, five serotype $A 7$, three serotype B1 and three serotype B2. Coxsackievirus B6 was not identified as a causative agent of aseptic meningitis in this study. Coxsackievirus B4 was identified as the dominant serotype in all years of the study, except in 2005, where B3 was the dominant serotype (Figure 3). Coxsackievirus B4 was the dominant serotype in all age groups, except for the group of 10-14 year-olds, in whom coxsackievirus B5 was the dominant serotype, and the 40-49 year-old patients, in whom coxsackievirus B3 was the dominant serotype (Figure 4). The

\section{FIGURE 2}

Proportion of aseptic meningitis patients with proven intrathecal antibody production against coxsackieviruses, Slovakia, 2005-2009 $(\mathrm{n}=480)$

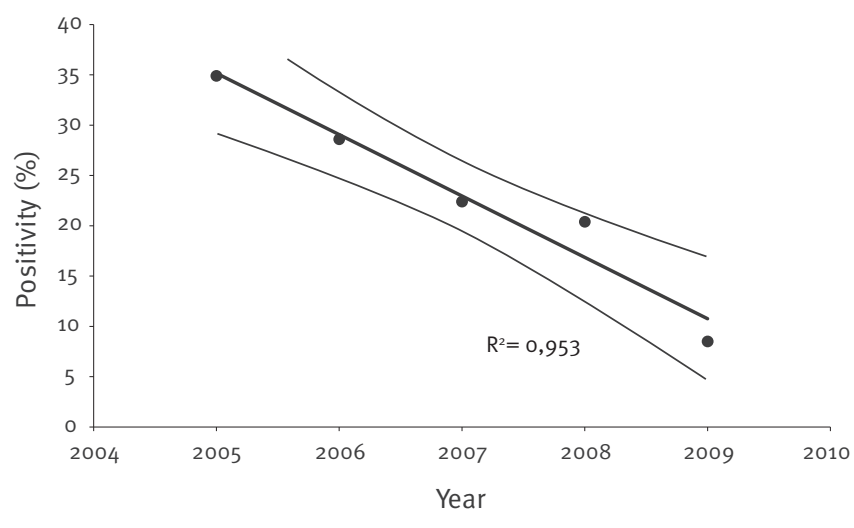

Linear trend (thick line) with 95\% confidence intervals (thin lines). 
proportion of 40-49 year-old patients in 2005 and 2006 was $21 \%$ and similar in 2007 (17\%), when B4 serotype was dominant.

We compared these results with the general prevalence of these eight coxsackievirus serotypes in the population by looking at the prevalence of virus-specific neutralising antibodies in serum samples as a marker of previous infection (Table). Antibodies against coxsackievirus B4 were the most prevalent in all years of the study, ranging between $73 \%$ and $81 \%$. Antibodies against other coxsackieviruses were less prevalent.

\section{Discussion and conclusion}

This paper relates the occurrence of infection with eight selected coxsackievirus serotypes to that of aseptic meningnitis in Slovakia. Unlike in other studies [5,6], a large proportion (78\%) of our patients were older than 20 years. This may partially be explained by the fact that the majority of samples included in the study were from hospital departments for adults.

\section{FIGURE 3}

Cosxackievirus serotypes causing aseptic meningitis, by year, Slovakia, 2005-2009 $(n=100)$

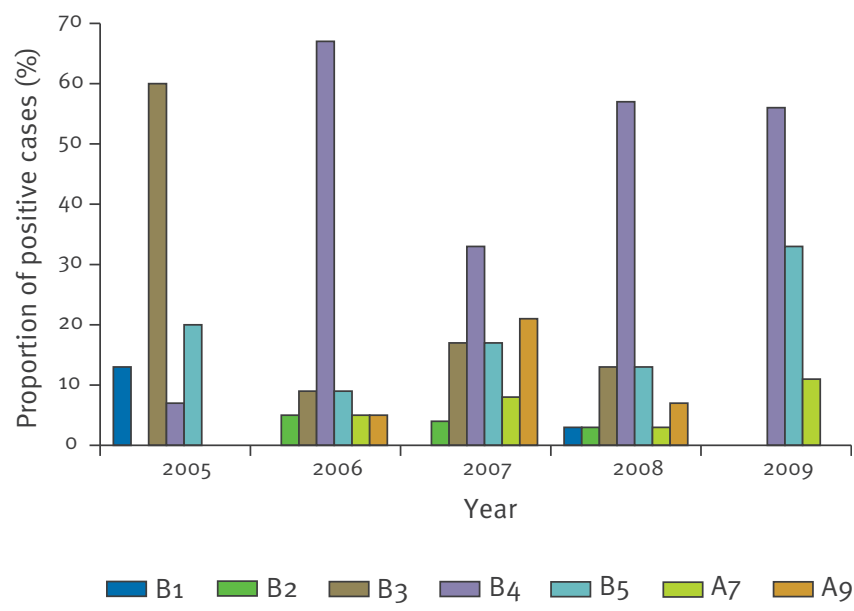

Almost all published reports on enteroviruses as the cause of diseases in humans are based on virus isolation from different biological materials such as stool, throat swabs or CSF $[5,21]$. Our study was based on the evidence of intrathecal production of virus-neutralising antibodies as a consequence of central nervous system infection with a given virus. This approach enables identification of the virus as the causative agent of an ongoing CNS disease without the necessity of virus isolation and identification, which may be difficult. On the other hand, the method allows detection of only a limited number of virus serotypes that are set up in the routine virus neutralisation assay.

Certain enteroviral serotypes can be endemic in a particular geographical area with little or only gradual changes over time [21]. Coxsackieviruses were established as the aetiological agent of CNS inflammatory disease in $21 \%$ of patients followed in our study. Coxsackieviruses are rare among enterovirus serotypes causing meningitis. Comparing the serotypes followed up in this study with other reports, different coxsackieviruses are dominant in different regions and times: Serotype $B_{5}$ was relatively more abundant in Hungary (2000-2008) [7] and Spain (1988-1997) [21], B5 and B3 in Belgium (1980-1994) [8], B5 and B4 in the United States (2002-2005) [22], B3 in Tunisia (1992-2003) [9] and B2 in Cyprus (2000-2002) [6]. Coxsackie B4 virus appeared to be the endemic serotype in Slovakia, responsible for most cases of coxsackieviral meningitis during the period of our study. This finding is supported by the fact that in all years of the study, the most prevalent antibodies in sera of meningitis patients were those against coxsackievirus B4. However, it should be emphasised that we studied only selected eight of the coxsackievirus serotypes that may be responsible for the inflammatory CNS disease in humans, and our results are therefore not fully comparable with other studies aimed to all HEV serotypes. Other enteroviral serotypes were not investigated here because of the limitations of the virus neutralisation test.

\section{FIGURE 4}

Cosxackievirus serotypes causing of inflammatory central nervous system disease, by age group, Slovakia, 2005-2009 (n=100)

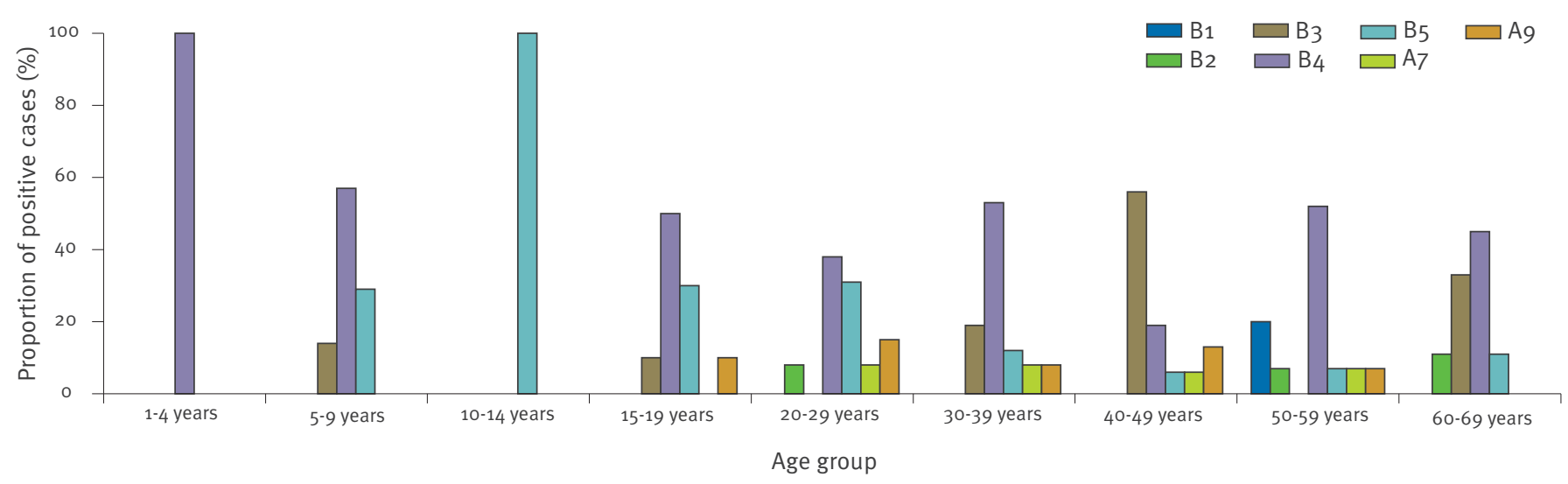


We observed a significant decrease during the study in the proportion of patients with coxsackieviral meningitis as evidenced by intrathecal production of virusspecific antibodies. We may speculate that this decline could be related to changes in the circulation of coxsackieviruses and other enteroviral serotypes in the Slovak population that are related to the modification of the polio vaccination programme when the Sabin live oral polio vaccine was replaced by the Salk inactivated vaccine in 2004 and other enteroviruses may have colonised the free living space, possibly interfering with the coxsackievirus strains we have here identified as declining. It should be taken in account that age, the characteristics of the biological agent and epidemiological conditions modulate the patterns of intrathecal immunoglobulin synthesis [14] and that possible alterations in the virulence of circulating enteroviruses may also lead to a change in the virus-specific intrathecal immune response pattern. In our previous seroprevalence study [23], we observed a consecutive decrease in proportion of patients that had antibodies against studied coxsackieviruses in the years 1985 to 2004 . In 2005 this trend stopped and a mild increase in seropositivity to all studied serotypes was observed.

In conclusion this study demonstrates that coxsackieviruses were a significant cause of viral meningitis in Slovakia. These viruses circulate in the population and the prevalence of antibodies against the studied serotypes did not change during the study period. The identified trend in the proportion of diseases caused by the studied viruses indicates that in the future, studies on the other non-polio enteroviruses, e.g. echoviruses, may become of greater importance in the diagnosis of CNS diseases.

\section{Acknowledgements}

This study was supported by a grant from the Ministry of Health of the Slovakia (MZSR 2006/12-SZU-07). We thank Shubhada Bopegamage for reading the article and giving valuable suggestions, and Iveta Jandová and Alica Stračinová for their technical assistance.

\section{References}

1. Chadwick DR. Viral meningitis. Br Med Bull. 2006;75-76:1-14.

2. Rotbart HA, Brennan PJ, Fife KH, Romero JR, Griffin JA, McKinlay MA, et al. Enterovirus meningitis in adults. Clin Infect Dis. 1998;27(4):896-8.

3. Ihekwaba UK, Kudesia G, McKendrick MW. Clinical features of viral meningitis in adults: Significant differences in cerebrospinal fluid findings among herpes simplex virus, varicella zoster virus and enterovirus infections. Clin Infect Dis. 2008;47(6):783-9.

4. Kupila L, Vuorinen T, Vainionpää R, Hukkanen V, Marttila RJ, Kotilainen P. Etiology of aseptic meningitis and encephalitis in an adult population. Neurology. 2006;66(1):75-80.

5. Atkinson PJ, Sharland M, Maguire H. Predominant enteroviral serotypes causing meningitis. Arch Dis Child. 1998;78(4):373-4.

6. Richter J, Koptides D, Tryfonos C, Christodoulou C. Molecular typing of enteroviruses associated with viral meningitis in Cyprus, 2000-2002. J Med Microbiol. 2006;55(pt 8):1035-41.

7. Kapusinszky B, Szomor KN, Farkas A, Takács M, Berencsi G. Detection of non-polio enteroviruses in Hungary 2000-2008 and molecular epidemiology of enterovirus 71, coxsackievirus A16 and echovirus 30. Virus Genes. 2010;40(2):163-73.

8. Druyts-Voets E. Epidemiological features of entero nonpoliovirus isolations in Belgium 1980-94. Epidemiol Infect. 1997;119(1):71-7.

9. Bahri O, Rezig D, Ben Nejma-Oueslati BB, Yahia AB, Sassi JB, Hogga N Yet al. Enteroviruses in Tunisia: virological surveillance over 12 years (1992-2003). J Med Microbiol. 2005;54(Pt 1):63-9.

10. Melnick JL. Enteroviruses: polioviruses, coxsackieviruses, echoviruses and newer enteroviruses. In: Fields BN, Knipe DM, Howley PM, Chanock RM, Melnick JL, Monath TP, et al., editors. Virology, 3rd ed. Philadelphia: Lippincott-Raven; 1996. p. $655-712$.

11. Roivainen M, Agboatwalla M, Stenvik M, Rysä T, Akram DS, Hovi T. Intrathecal immune response and virus-specific immunoglobulin $\mathrm{M}$ antibodies in laboratory diagnosis of acute poliomyelitis. J Clin Microbiol. 1993;31(9):2427-32.

12. Hovi T, Stenvik M, Kinnunen E. Diagnosis of poliomyelitis by demonstration of intrathecal synthesis of neutralizing antibodies. J Infect Dis. 1986;153(5):998-9.

13. Dorta-Contreras AJ. Intrathecal synthesis of immunoglobulins in Neisseria meningitidis and Echovirus 6 meningoencephalitis. J Mol Neurosci. 1999;12(2):81-7.

14. Dorta-Contreras AJ. Pattern of intrathecal immunoglobulin synthesis in pediatric patients with infectious meningoencephalitis. Biotecnol Apl. 2006;23(4):382-6.

15. Derfuss T, Hohlfeld R, Meinl E. Intrathecal antibody (IgG) production against human herpesvirus type 6 occurs in about $20 \%$ of multiple sclerosis patients and might be linked to a polyspecific B-cell response. J Neurol 2005;252(8):968-71.

16. Puccioni-Sohler M, Soares CN, Papaiz-Alvarenga R, Castro MJC, Faria JC, Peralta JM. Neurologic dengue manifestations associated with intrathecal specific immune response. Neurology 2009;73(17):1413-7.

17. Melnick JL. My role in the discovery and classification of the enteroviruses. Annu Rev Microbiol. 1996;50:1-24.

\section{TABLE}

Prevalence of antibodies against coxsackieviruses B1 to B6, A7 and A9 in sera of aseptic meningitis patients, Slovakia, 2005-2009 $(\mathrm{n}=480)$

\begin{tabular}{|l|c|c|c|c|c|c|c|c|c|}
\hline \multirow{2}{*}{ Year } & \multirow{2}{*}{$\begin{array}{c}\text { Number } \\
\text { of patients }\end{array}$} & \multicolumn{9}{c|}{ Number of patients with serum antibodies } \\
& & B1 & B2 & B3 & B4 & B5 & B6 & A7 & A9 \\
\hline 2005 & 43 & $15(35)$ & $22(51)$ & $33(77)$ & $35(81)$ & $22(51)$ & $2(5)$ & $30(70)$ & $24(56)$ \\
\hline 2006 & 77 & $24(31)$ & $43(56)$ & $44(57)$ & $59(77)$ & $36(47)$ & $3(4)$ & $51(66)$ & $46(60)$ \\
\hline 2007 & 107 & $35(33)$ & $56(52)$ & $73(68)$ & $87(81)$ & $49(46)$ & $13(12)$ & $68(64)$ & $72(67)$ \\
\hline 2008 & 147 & $55(37)$ & $87(59)$ & $94(64)$ & $113(77)$ & $83(56)$ & $13(9)$ & $94(64)$ & $90(61)$ \\
\hline 2009 & 106 & $36(34)$ & $67(63)$ & $59(56)$ & $77(73)$ & $59(56)$ & $10(9)$ & $55(52)$ & $51(48)$ \\
\hline Total & 480 & $165(34)$ & $275(57)$ & $303(63)$ & $371(77)$ & $249(52)$ & $41(9)$ & $298(62)$ & $283(59)$ \\
\hline
\end{tabular}


18. Parks WP, Queiroga LT, Melnick JL. Studies of infantile diarrhea in Karachi, Pakistan. II. Multiple virus isolations from rectal swabs. Am J Epidemiol. 1967;85(3):469-78.

19. Koskiniemi ML, Vaheri A. Diagnostic value of cerebrospinal fluid antibodies in herpes simplex virus encephalitis. J Neurol Neurosurg Psychiatry. 1982;45(3):239-42.

20. Melioli G, Pedullá D, Merli AL, Arata L, Leonardi A. A simple method to detect intrathecal production of specific antimeasles antibodies in cerebrospinal fluid during subacute sclerosis panencephalitis. Diagn Microbiol Infect Dis. 1985;3(5):411-7.

21. Trallero G, Casas I, Tenorio A, Echevarria JE, Castellanos A, Lozano A. et al. Enteroviruses in Spain: virological and epidemiological studies over 10 years (1988-97). Epidemiol Infect. 2000;124(3):497-506.

22. Khetsuriani N, Kutateladze T,Zangaladze E, Shutkova T, Peñaranda S, Nix WA, et al. High degree of genetic diversity of non-polio enteroviruses identified in Georgia by environmental and clinical surveillance, 2002-2005. J Med Microbiol. 2010;59(Pt 11):1340-7.

23. Sojka M, Bopegamage S, Petrovičová A. Circulation of coxsackieviruses in the Slovak population in 1985-2007. Epidemiol Mikrobiol Imunol. 2008;57(2):57-60. 